INFO ARTIKEL

Riwayat Artikel:

Diterima : 1 Agustus 2019

Disetujui : 15 Agustus 2019

\title{
GEOGRAFI
}

\section{PENGEMBANGAN DAYA TARIK RUMAH RAKIT SEBAGAI DESTINASI WISATA SUNGAI}

\author{
Maharani Oktavia ${ }^{1}$, Ahmad Zamhari ${ }^{2}$, Mardiana Sari ${ }^{3}$ \\ ${ }^{1}$ Program StudiPendidikanGeografi, Universitas PGRI Palembang \\ ${ }^{2}$ Program StudiPendidikanSejarah,Universitas PGRI Palembang \\ ${ }^{3}$ Program StudiPendidikanBahasaIndonesai, Universitas PGRI Palembang \\ (《)maharangeo@gmail.com ${ }^{1}$
}

\begin{abstract}
ABSTRAK
Otonomi daerah menyebabkan pemerintah membuat berbagai jenis wisata yang cenderung monoton serta kurangnya konsep wisata sehingga destinasi wisata yang bermunculan cenderung kurang diminati, akibatnya destinasi wisata tersebut tidak mampu bertahan lama. Kota Palembang merupakan salah satu destinasi wisata sungai yang memiliki peluang dalam meningkatkan pembangunan dengan berbagai daya tarik salah satunya rumah rakit. Rumah rakit adalah rumah yang dibangun di atas rakit yang terbuat dari kayu, namun jejak sejarah itu kini kian lama menghilang dan terus menerus mengalami degradasi budaya sehingga diperlukan identifikasi terhadap daya tarik yang dimiliki dan arahan pengembangan rumah rakit sebagai destinasi wisata sungai yang ada di Kota Palembang. Pengumpulan data bersumber dari data primer dan data sekunder. Data primer diperoleh dari hasil survey, kuesioner dan wawancara. Sedangkan data sekunder diperoleh dari instansi atau dinas yang terkait. Analisis pengembangan daya tarik dikaji dengan pendekatan SWOT. Hasil penelitian menyatakan bahwa potensi daya tarik alam serta potensi budaya yang khas memiliki daya tarik wisata yang indah, unik dan otentik berbasis kearifan lokal. Pengembangan daya tarik rumah rakit sebagai destinasi wisata sungai musi meliliki kelemahan berupa fasilitas yang kurang memadai, tidak adanya atraksi wisata, kurangnya peran serta pemerintah dalam hal promosi yang lebih iconik atau instagramable di zaman digital serta perlunya slogan dalam penguatan promosi wisata. Kekuatan wisata rumah rakit merupakan wisata alam yang berbasis budaya serta sebagai peninggalan sejarah.
\end{abstract}

Kata Kunci: Pengembangan, DayaTarik, Destinasi wisata

\section{PENDAHULUAN}

Pengembangan pariwisata di Indonesia semakin maju dan terus berkembang hal ini terlihat dari program Visit Indonesia Year kemudian menjadi slogan "Wonderful Indonesia" yang unik dan menarik. Setiap negara mempunyai logo dan slogan pariwisata selain untuk meningkatkan jumlah pengunjung juga secara tidak langsung dapat meningkatkan perbaikan infrastruktur khususnya bagi sektor pariwisata dan kebudayaan itu sendiri maupun bagi sektor lain. Setiap kota atau kabupaten yang ada di Indonesia berlomba-lomba untuk mengembangkan destinasi utama dan branding baru yang menyangkut dalam unsur 3A (atraksi, aksesibilitas dan amenitas) dalam memudahkan wisatawan berkunjung ke destinasi - destinasi wisata. Setiap kota atau kabupaten yang ada di Indonesia berlomba-lomba untuk mengembangkan destinasi wisata baru. 
Otonomi daerah memberikan kewenangan kepada masing-masing kabupaten/kota, namun di sisi lain justru menimbulkan persaingan bauran produk yang belum terspesiaisasi (Prihatno,2010). Dengan adanya otonomi daerah menyebabkan pemerintah membuat berbagai destinasi-destinasi wisata yang cenderung monoton terhadap daya tarik dan kurangnya konsep wisata serta prilaku masyarakat yang kurang mendukung terhadap kelestarian budaya sehingga destinasi wisata yang bermunculan cenderung kurang diminati, akibatnya destinasi wisata tidak mampu bertahan lama. Padahal daya tarik wisata yang berkualitas merupakan faktor kunci yang sangat menenukan minat berkunjung wisatawan (Basiya \& Rozak, 2012); (Sofyan\& Widiyanto,2015);(Nasution et al.,2009); (Hermawan, 2017). Daya tarik wisata yang unggul dan berkualitas merupakan faktor kunci yang menetukan motivasi wisatawan untuk berwisata, serta sebagai alasan fundamental yang menjadi pertimbangan mengapa seseorang memilih satu destinasi (Ritchie and Crouch, 2003).

Destinasi wisata sungai menjadi tujuan utama Dinas Pariwisata Kota Palembang dalam memperhitungkan peluang yang dimiliki dalam rangka meningkatkan pembangunan yang elok dan bertaraf internasional serta memberikan perhatian khusus untuk menarik jumlah kunjungan wisatawan dalam negeri dan luar negeri. Kota Palembang merupakan salah satu daerah tujuan wisata yang memiliki berbagai daya tarik wisata salah satunya rumah rakit. Rumah rakit adalah rumah yang dibangun di atas rakit yang terbuat dari kayu. Rumah ini mengapung di tepi Sungai Musi. Agar tidak hanyut terbawa arus, rumah diikat pada serdang (penambat). Rumah rakit sudah ada sejak zaman kesultanan Palembang. Pada zaman kesultanan Palembang, semua warga asing harus menetap di atas rakit termasuk warga Inggris, Spanyol, Belanda, Cina, Campa, Siam, bahkan kantor Dagang Belanda pertama di atas rakit, lengkap dengan gudangnya. Rumah Rakit ini selain sebagai tempat tinggal juga berfungsi juga sebagai gudang industri kerajinan. Bahkan pada tahun 1900 an dibangun Rumah Sakit diatas rakit, karena dianggap mereka lebih sehat dan indah karena dapat melihat kehidupan di sepanjang
Sungai Musi, namun jejak sejarah itu kini kian lama menghilang dan terus menerus mengalami degradasi budaya sehingga diperlukan identifikasi terhadap daya tarik yang dimiliki dan arahan pengembangan rumah rakit sebagai destinasi wisata yang ada di Kota Palembang.

Rumah rakit merupakan salah satu destinasi wisata sungai di Kota Palembang yang mempunyai potensi wisata budaya yang harus di jaga kelestariannya, ternyata dalam realisasinya masih mengalami kendala dalam pengelolaan dan peningkatan kualitas baik dari pemerintah maupun rendahnya perhatian dari masyarakat setempat dan dapat menjadi masukan dalam peningkatan kesejahtaraan masyarakat dan pembuka lapangan pekerjaaan dalam meningkatkan daya tarik maupun atraksi wisata. Pengembangan daya tarik rumah rakit sebagai destinasi wisata sungai perlu adanya optimalisasi pengembangan baik dari daya tarik/atraksi, aksesibilitas, dan amenitas. Untuk itu perlu perencanaan yang bersifat holistik terhadap arahan pengembangan daya tarik rumah rakit sebagai destinasi wisata.

\section{METODOLOGI PENELITIAN}

Pengumpulan data penelitian ini bersumber dari data primer. Data primer diperoleh dari hasil survey, meliputi data observasi lapangan dengan mengamati secara langsung lokasi-lokasi penelitian dan mendapatkan suatu data dengan mencatat respon dan kejadian sehingga dapat mendeskripsikan kondisi yang sebenarnya.

Metode penentuan sampel secara nonprobabiliy sampling artinya tidak memberi kemungkinan yang sama bagi setiap unsur populasi untuk dipilih karena tidak diketahui dan dikenal populasi sebenarnya. (Nasution, 1987). Teknik pengambilan sampelnya secara sampling aksidental berdasarkan siapa saja yang kebetulan ditemui pada saat melakukan penelitian.

Analisis data dalam penelitian ini dilakukan dengan berbagai cara, sesuai dengan sifat data yang dianalisis, yaitu dengan menggunakan tabel frekuensi deskriptif kualitatif, kriteria dan klasifikasi. Sedangkan untuk analisis pengembangan mengunakan SWOT. Sthepen 
(1999) dalam Murdani (2014) Analisis SWOT merupakan suatu analisis yang berdasarkan pada kekuatan (Strengths), kelemahan (weakness), peluang (Opportunities), kesempatan serta Ancaman (threat).

\section{HASIL DAN PEMBAHASAN}

Rumah rakit adalah rumah yang dibangun di atas rakit yang terbuat dari kayu. Rumah ini mengapung di tepi Sungai Musi. Rumah rakit sudah ada sejak zaman kesultanan Palembang. Pada zaman kesultanan Palembang, semua warga asing harus menetap di atas rakit termasuk warga Inggris, Spanyol, Belanda, Cina, Campa, Siam, bahkan kantor Dagang Belanda pertama di atas rakit, lengkap dengan gudangnya. Rumah Rakit ini selain sebagai tempat tinggal juga berfungsi juga sebagai gudang industri kerajinan.

\section{Potensi Rumah Rakit}

Rumah rakit memiliki bentuk persegi panjang yang berukuran kurang lebih sekitar 36 sampai 64 meter persegi, serta mempunyai bentuk atap mirip pelana. Atap rumah ini disebut sebagai atap kajang yang terbuat dari daun nipah kering.Tembok rumah rakit terbuat dari kayu dengan serat yang cukup padat serta memiliki fondasi yang berasal dari bambu yang berusia cukup tua agar dapat bertahan lama. Bambu besar yang memiliki ukuran diameter variatif ini digunakan sebagai fondasi rumah dengan cara saling diikatkan satu dengan yang lainnya, kemudian diikatkan dengan sebuah pasak. Rumah rakit mempunyai potensi wisata baik wisata alam maupun wisata sejarah, hal ini terlihat bahwa rumah rakit telah ada dari zaman kesultanan Palembang. Sedangkan untuk wisata alam rumah rakit menjadi daya tarik tersendiri sebagai tempat hiburan dan rekreasi. Kondisi geografis membuat fungsi rumah rakit tidak hanya sebagai alat transportasi untuk membawa orang yang ada di atasnya ke suatu tempat, tetapi juga untuk tempat tinggal serta sebagai mata pencahaian. Hal ini dapat dilihat pada gambar $1 \mathrm{di}$ bawah ini.

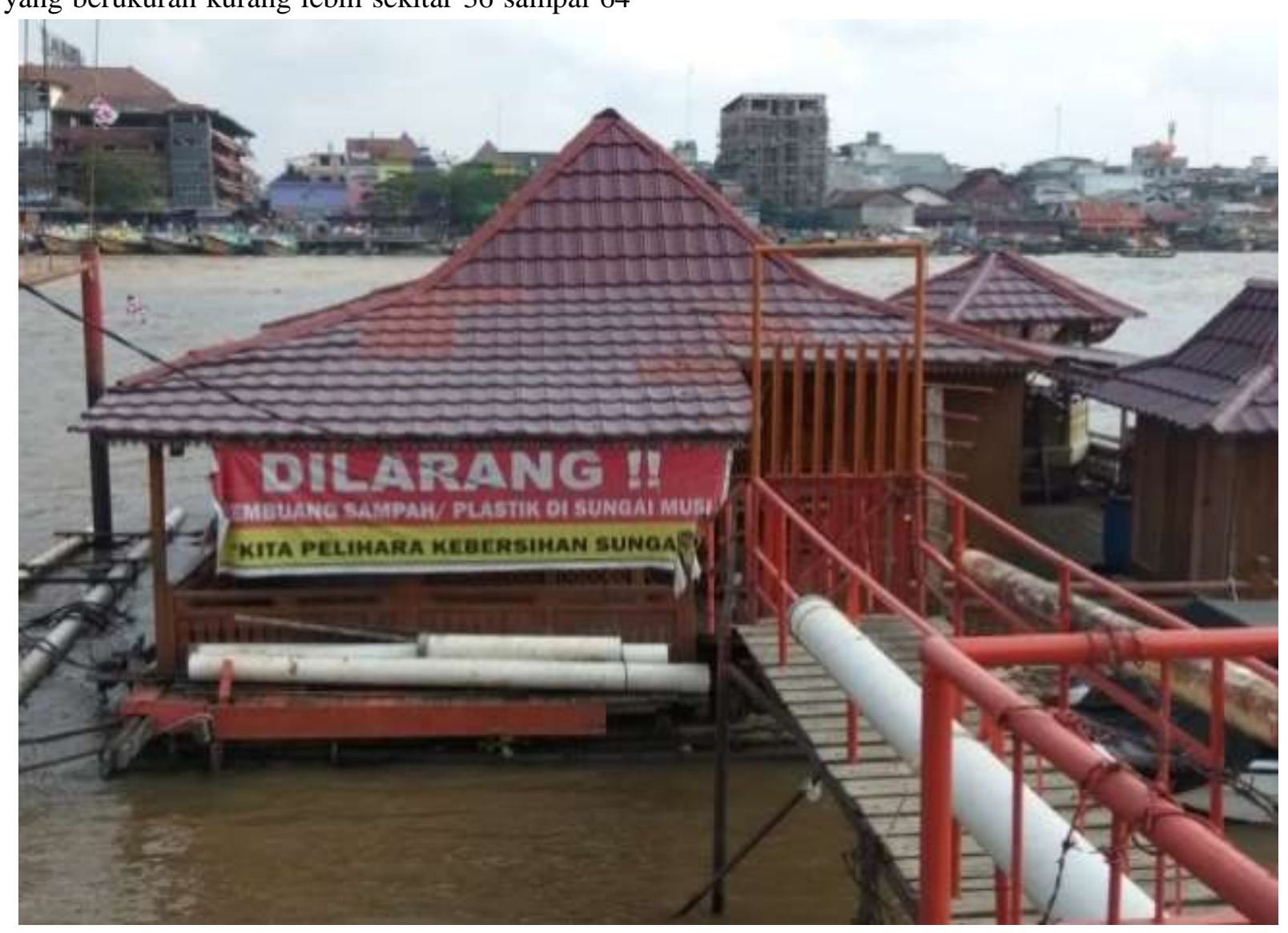

Gambar 1. Wisata Rumah Rakit 
Rumah rakit sekarang termasuk dalam salah satu objek wisata yang terus dilihat dan dikembangkan dan menjadi destinasi wsiata di Kota Palembang. Destinasi adalah tempat yang dikunjungi dengan waktu yang signifikan selama perjalanan seseorang yang di bandingkan dengan tempat lain yang dilalui selama perjalanan (Pitana dan Putu, 2009). Daya tarik wisata dalam penelitian terdahulu telah terbukti menjadi salah satu faktor utama yang wajib di perhitungkan dalam perencanaan destinasi wsiata, karena akan sangat menentukan tingkat kepuasan wisatawan (Naidoo, Ramseook-Munhurrun, \& Seegoolom, 2011). Undang-undang Nomor 10 tentang Kepariwisataan bahwa unsur produk wisata atau destinasi setidaknya ada 3 yaitu : Atraksi/ daya tarik wisata, Ammenitas dan Aksesibilitas biasa di singkat 3 A pariwisata. Pengembagan destinasi wisata pada tingkatan tapak lahan setidaknya memperhitungkan 3 poin kunci tersebut. Kemudian menurut Endang (2008:19) potensi di daerah tujuan wisata dipengaruhi adanya 4 pendekatan antara lain: atraksi, aksesibilitas dan amenitas.

\section{Daya Tarik Rumah Rakit sebagai Objek Wisata}

Persepsi pengunjung terhadap daya tarik objek wisata rumah rakit dapat dilihat dari atraksi, amenitas dan aksesibilitas.

\section{Atraksi}

Persepsi responden terhadap atraksi yang ada di objek wisata Rumah rakit kurang menarik sebesar $38 \%$, sedangkan $33 \%$ responden menjawab tidak menarik, dan $13 \%$ responden menjawab menarik. Hal ini dapat di lihat pada gambar 2.

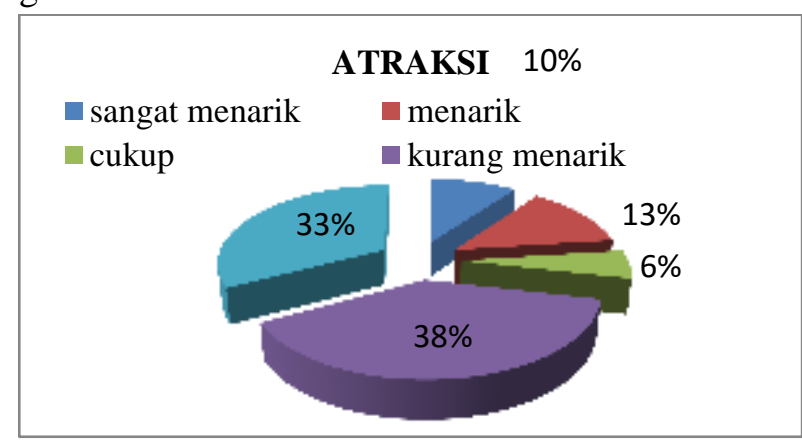

Gambar 2. Persepsi responden terhadap atraksi wisata rumah rakit

\section{Amenitas}

Persepsi responden terhadap atraksi yang ada di objek wisata Rumah rakit kurang menarik sebesar $30 \%$, sedangkan $27 \%$ responden menjawab tidak menarik, dan $17 \%$ responden menjawab menarik. Hal ini dapat di lihat pada gambar 3 .

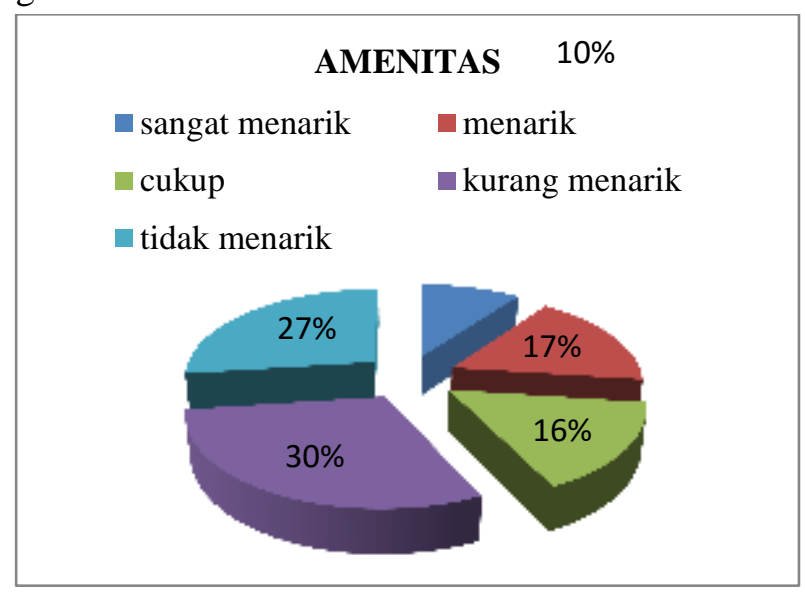

Gambar 3. Persepsi responden terhadap amenitas wisata rumah rakit

3. Aksesibilitas

Persepsi responden terhadap atraksi yang ada di objek wisata Rumah rakit sangat menarik sebesar $42 \%$, sedangkan $20 \%$ responden menjawab menarik, dan $11 \%$ responden menjawab kurang menarik. Hal ini dapat di lihat pada gambar 4.

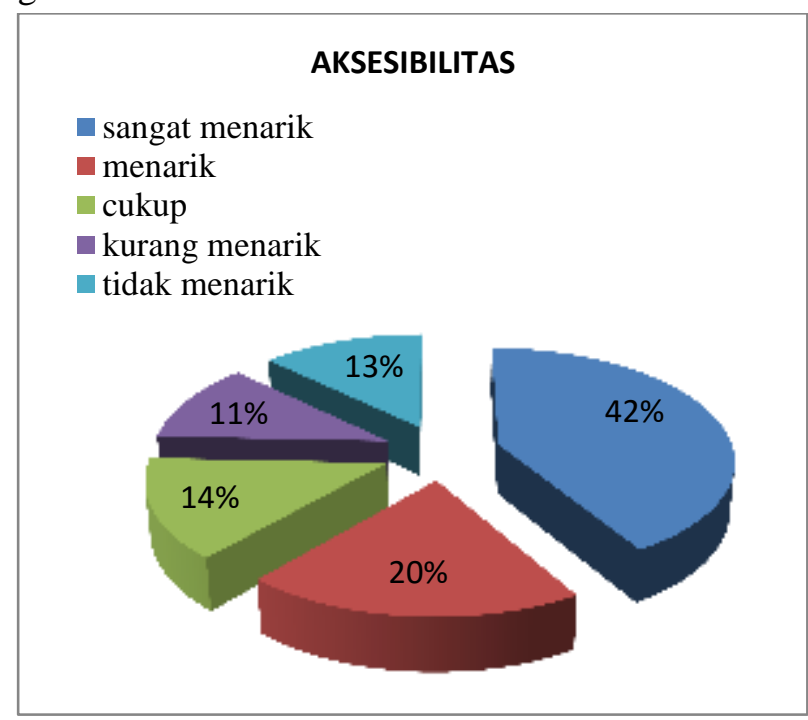

Gambar 4. Persepsi responden terhadap aksesibilitas wisata rumah rakit

Peta lokasi penelitian dapat dilihat pada gambar 5 . 


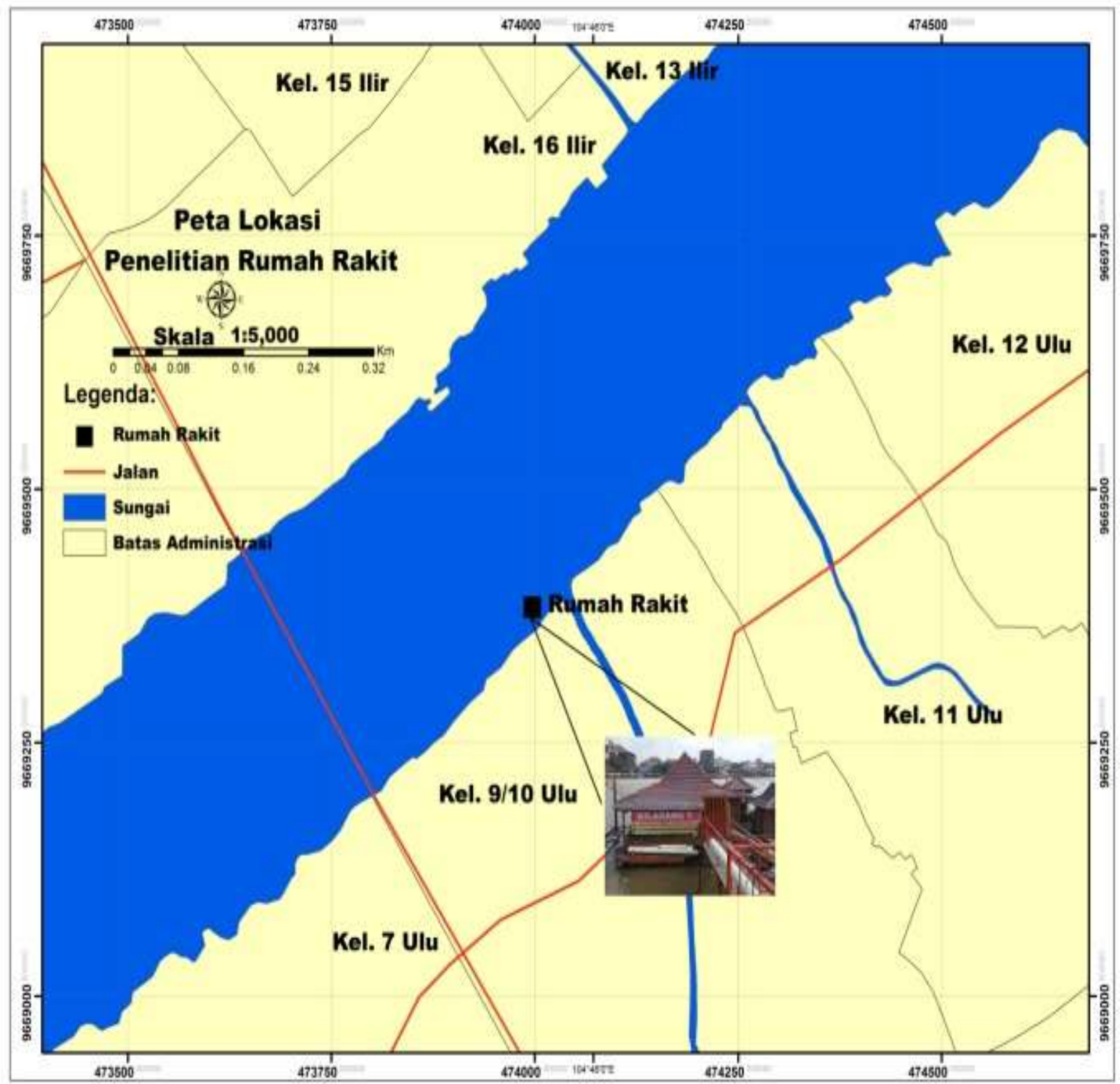

Gambar 5. Peta Lokasi Penelitian Rumah Rakit

Pengembangan Objek Wisata Rumah Rakit sebagai Destinasi Sungai

Pendekatan pengembangan pariwisata dengan mendasarkan pada pemikiran geografi dengan pandangan keruangan, maka pengembangan pariwisata dapat pula didasarkan pada teori pengembangan wilayah dengan menggunakan konsep pusat pertumbuhan oleh Christaler dalam
Sumaatmadja (1992), pariwisata di suatu wilayah merupakan pusat pertumbuhan (growth center) di wilayah tersebut. Dalam penelitian ini, pendekatan utama yang digunakan adalah pendekatan keruangan karena penelitian ini lebih menekankan pada pendeskripsian daya tarik objek wisata yang dimiliki, lokasi dan destinasi objek wisata, serta arahan pengembangan ruang objek wisata tersebut. 


\begin{tabular}{|c|c|c|}
\hline FAKTOR INTERNAL & STRENGTHS (S) /KEKUATAN & WEAKNESSES (W) /KELEMAHAN \\
\hline FAKTOR EKSTERNAI & $\begin{array}{l}\text { - Wisata alam /wisata sungai menjadi daya tarik wisata } \\
\text { - Aksesibilitas menuju objek wisata cukup mudah } \\
\text { menjangkaunya, hal ini dapat diketahui jarak tempuh dan } \\
\text { waktu yang cukup dekat, lokasinya dekat dengan kota dan } \\
\text { dapat dilalui baik menggunakan ketek (perahu) maupun jalan } \\
\text { darat. } \\
\text { - Sebagai rekam jejak sejarah sejak zaman kesultanan } \\
\text { Palembang }\end{array}$ & $\begin{array}{l}\text { - Atraksi wisata tidak pernah sama sekali dan tidak adanya } \\
\text { keanekaragaman objek wisata yang lain. } \\
\text { - Amenitas objek wisata rumah rakit masih kurang baik dan kurang } \\
\text { terpelihara serta sistem keamanan di wisata masih kurang (tidak } \\
\text { diperbolehkan untuk masuk ke dalam rumah rakit, karena objek } \\
\text { tersebut masih belum di kelola dgn baik) } \\
\text { - Ketersediaan sarana dan prasarana kurang memadai (seperti : sarana } \\
\text { rekreasi, sarana atraksi, tempat duduk, restoran/cafe, gazebo, toko } \\
\text { souvenir, guide) }\end{array}$ \\
\hline OPPORTUNITIES (O)/KESEMPATAN & S + O Arahan Pengembangan Strategi (Progresif/Aktif) & W + O Meningkatkan Peran PEMDA, Yayasan, Masyarakat \\
\hline $\begin{array}{l}\text { - Terbukanya kesempatan kerja dan peluang usaha } \\
\text { - Peningkatan pendapatan masyarakat dan pendapatan asli daerah } \\
\text { (PAD) Kota Palembang } \\
\text { - Masuknya investasi usaha wisata dari investor lokal maupun } \\
\text { asing } \\
\text { - Terbukanya kesempatan promosi pariwisata dengan media yang } \\
\text { lebih modern ke dalam dan luar negeri } \\
\text { - Terbukanya kesempatan untuk membuat keterkaitan dengan } \\
\text { objek wisata lain di sekitarnya }\end{array}$ & $\begin{array}{l}\text { - Membuat slogan wisata dalam penguatan promosi } \\
\text { - Menbuat logo potensi daerah sebagai promosi wisata yang } \\
\text { lebih iconik dan modern } \\
\text { - Mengemas atraksi alam dan budaya untuk menarik investor } \\
\text { lokal dan asing dalam pengembangan objek wisata } \\
\text { - Membuat promosi baik menggunakan media cetak (spanduk, } \\
\text { banner, iklan di koran, majalah, buku, sticker, pamflet dan } \\
\text { flyer) maupun elektronik atau media internet (media banner } \\
\text { website,instagram, twitter, facebook ads dan google } \\
\text { AdWordsd). }\end{array}$ & $\begin{array}{l}\text { - Memperbaiki dan menambah jumlah sarana dan prasarana yang } \\
\text { kurang memadai serta melengkapi kekurangannya } \\
\text { - Menumbuhkan kerjasama antar PEMDA, Yayasan dan Masyarakat } \\
\text { dalam menjaga kelestarian, memelihara sarana - pra sarana dan } \\
\text { dalam mengemas atraksi pariwisata } \\
\text { - Menjalin kerjasama dengan pengelola objek wisata lain agar bisa } \\
\text { dibuat paket wisata dengan objek-objek lain di sekitarnya }\end{array}$ \\
\hline THREATS (T) /ANCAMAN & S + T Aktif Membuka Peluang & 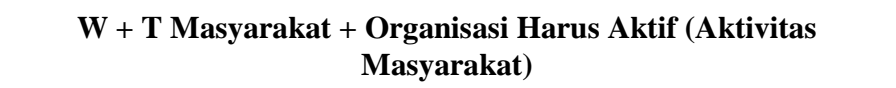 \\
\hline $\begin{array}{l}\text { - Belum adanya Atraksi wisata yang ditawarkan membuat } \\
\text { pengunjung tidak bertahan lama di lokasi wisata } \\
\text { - Sepinya pengunjung mengakibatkan sarana prasarana tidak } \\
\text { terpelihara } \\
\text { - Rendahnya kualitas SDM dalam mengembangkan wisata } \\
\text { - Kurangnya kerjasama antara pemilik/ pengelola dengan } \\
\text { pemerintah daerah dalam hal pengembangan wisata secara } \\
\text { berkesinambungan } \\
\text { - Kurangnya kesadaran masyarakat dalam memelihara objek } \\
\text { wisata rumah rakit }\end{array}$ & $\begin{array}{l}\text { - Membuat paket wisata perjalanan yang terkait dengan objek } \\
\text { wisata lain di sekitar rumah rakit } \\
\text { - Mengembangkan sarana transportasi yang lebih refrentatif dan } \\
\text { modern } \\
\text { - Membuat kegiatan atau event-event kuliner yang khas } \\
\text { - Membuat usaha ekonomi kreatif yang bernilai guna }\end{array}$ & $\begin{array}{l}\text { - Meningkatkan kualitas SDM dengan pembinaan khusus bagi } \\
\text { masyarakat lokal dan pemberdayaan masyarakat } \\
\text { - Bekerjasama antar masyarakat dalam memelihara kebersihan } \\
\text { lingkungan sekitar } \\
\text { - Dapat menarik pungutan ringan untuk pemeliharaan sarana } \\
\text { kebersihan dan MCK agar bisa dikelola dan dipelihara dengan lebih } \\
\text { baik oleh masyarakat } \\
\text { - Meningkatkan kondisi sosial ekonomi masyarakat setempat }\end{array}$ \\
\hline
\end{tabular}




\section{SIMPULAN}

Pengembangan daya tarik rumah rakit sebagai destinasi wisata sungai musi meliliki kelemahan berupa fasilitas yang kurang memadai, tidak adanya atraksi wisata, kurangnya peran serta pemerintah dalam hal promosi yang lebih iconik atau instagramable di zaman digital serta perlunya slogan dalam penguatan promosi wisata. Kekuatan wisata rumah rakit merupakan wisata alam yang berbasis budaya dan sejarah.

\section{DAFTAR PUSTAKA}

Antonim. (2009). Undang - Undang Nomor 10 Tahun 2009 Tentang Kepariwisataan. Indonesia

Basiya,R., \& Rozak, H.A. (2012). Kualitas daya tarik wisata, kepuasan dan Niat Kunjungan kembali Wisatawan Mancanegara di Jawa Tengah. Jurnal Ilmiah Dinamika Kepariwisataan II.

Endang H. (2008). Potensi dan Pengembangan Kampung Etnik Arab Sebagai Aset Wisata di Kota Surakarta. Laporan Tugas Akhir. Program Studi D3 Usaha Perjalanan Wisata (USM), Surakarta.

Hermawan H. (2017). Pengembangan Destinasi Wisata pada tingkat Tapak Lahan dengan Pendekatan Analisis SWOT. Jurnal Pariwisata. Vo.IV.No. 2

Murdani, Taufik. (2014). Studi Pengembangan Objek Wisata Lubuak Bonta Di Kecamatan 2x11 Kayu Tanam Kabupaten Padang Pariaman.
Naidoo, P., Ramseook-Munhurrun, P., \& Seegoolam, P. (2011). An Assessment of Visitor Satisfaction with Nature-Based Tourism Attractions

Nasution, S. (1987). Metode Reseach. Penelitian Ilmiah. Bandung: Penerbit JemmarsL;

Nasution, S., Nasution , M.A., \& Dinamika. J. (2009). Persepsi Wisatawan Mancanegara Terhadap Kualitas Objek dan Daya Tarik Wisata (ODTW) Sumatera Utara.

Pitana, I. Gede dan G. Putu. (2009). Sosiologi Pariwisata.

Prihatno. (2010). Memulihkan Citra Daerah Istimewa Yogyakarta Untuk Meningkatkan Jumlah Wisatawan. Wahana Informasi Pariwisata: MEDIA WISATA

Ritchie, J. R.Brent dan Geoffrey Ian Crouch. (2003). The Competitive Destination: A Sustainable Tourism Perpective. Cabi.

Sofyan, S., \& Widiyanto. I. (2015). Analisis Pengaruh Daya Tarik Wisata dan Kualitas Pelayanan terhadap Minat Berkunjung Ulang Pengunjug dengan Kepuasan Pengunjung sebagai variabel Intervening (Studi pada Cagar Budaya Gedung Lawang Sewu). Fakulas Ekonomi dan Bisnis.

Sumaatmadja, N. (1992). Studi Geografi suatu pendekatan dan Analisa keruangan. Bandung. Alumni. 